\title{
Memorias apocalípticas, administrativas y campesinas: por una crítica de la memoria del sandinismo ${ }^{1}$
}

\author{
Leonel Delgado Aburto \\ Universidad de Chile \\ ldelga_ni@yahoo.com
}

RESUMEN: Este artículo plantea que la memoria del sandinismo está marcada por la labor gubernamental ejercida por esta fuerza política en los años ochenta, la que ahora aparece combinada con el liberalismo global. Además, la memoria sandinista puede proyectarse en un espacio latinoamericano de cambios, para lo cual este texto reflexiona sobre la perspectiva de Julio Cortázar sobre la revolución sandinista y el momento global y distópico en que se desenvolvió. Un tercer aspecto abordado es la memoria campesina como elemento omitido por la memoria sandinista predominante.

Palabras Clave: Revolución sandinista, memoria, Cortázar, liberalismo, memoria campesina.

Parte de la investigación para desarrollar este texto está asociada con mi proyecto de investigación sobre la transnacionalidad en la literatura centroamericana, Proyecto FONDECYT número 1120268, del que soy investigador responsable. Agradezco a los lectores anónimos de este texto por sus valiosas sugerencias. 


\section{APOCALYPTIC, ADMINISTRATIVE AND PEASANT MEMORIES:}

For A CRITIQUe OF THE MEMORY OF SANDINISMO

AвSTRACT: This article argues that the memory of the Sandinista revolution is permeated by the work of the Sandinistas ruling Nicaragua during the 1980s, and that now that memory is mixed with global liberalism. Furthermore, the Sandinista memory can be projected to a Latin American range of changes. Following that idea, my text analyzes Julio Cortazar's perspective on the Sandinista revolution and the global and dystopian moment of its development. A third aspect considered is the memory the peasants as an absent element in the leading Sandinista memory.

Keywords: Sandinista revolution, memory, Cortázar, liberalism, peasant memory.

Previo al actual auge de los estudios de memoria en América Latina, la cuestión de la memoria social y subalterna en Centroamérica estuvo dominada por los debates en torno al testimonio literario, su estética y representatividad ${ }^{2}$. Solo en años recientes se ha comenzado a problematizar la cuestión de las prácticas de la memoria en un campo cultural más diversificado, así como a pensar la correspondencia para el caso centroamericano de la teorización predominantemente elaborada a partir de experiencias del Cono Sur ${ }^{3}$. Tomando como escenario tal momento transicional y en progreso, me gustaría revisar en este ensayo la cuestión de la memoria del sandinismo ${ }^{4}$ con el ánimo de aportar a un eventual debate en torno a la memoria de la que fue quizá la última revolución moderna, o "el último evento en exhibir las características de una revolución en el

2 De entre la abundante literatura al respecto, ver la antología de Beverley y Achugar, La voz del otro.

3 Ver al respecto, especialmente sobre la memoria comunitaria e indígena: Cortez, "La construcción local de la memoria".

4 Me refiero en este caso al sandinismo del Frente Sandinista, organización guerrillera surgida en los años sesenta y que toma el poder en 1979. Me ocupo acá de la memoria postgubernamental del sandinismo. La memoria del sandinismo original, fundado en la guerrilla de Augusto Sandino durante los años veinte y treinta presenta otras problemáticas y pertenece una genealogía que no abordo en este texto. 
sentido tradicional" (Keucheyan 7) ${ }^{5}$. Coincido con Saldaña-Portillo (112) cuando señala que el destino de la revolución sandinista fue decidido por el campesinado. En efecto, el alzamiento campesino en contra del gobierno revolucionario - los llamados "contras" - señaló un rompimiento crucial entre el proyecto y sus representados, así como entre revolución nacionalista y sujeto social. Sin embargo, la memoria (personal y escrita) de la revolución sandinista que circula más y tiene más resonancia (textos como los de Gioconda Belli o Ernesto Cardenal) ${ }^{7}$ es elaborada por la elite política y literaria, lo que instala, o da continuidad, a un hiato característico del contexto nicaragüense y latinoamericano. Esa distancia no es otra que la de urbe y extramuros, ciudad y campo, que tiene también resonancias de división de clase, etnia y raza ${ }^{8}$. Considero en este ensayo que el debate y la teorización de la memoria del sandinismo deben hacerse cargo de ese escenario de división y distancia. Pero, además, que esa problemática debe desplegarse como asunto histórico, es decir, considerando la posibilidad de una lectura totalizante que conecte la microhistoria campesina con las coordenadas generales de los cambios económicos y políticos del contexto. En este caso, menos que la economía y la política, me interesan los ejes intelectuales con los que se puede pensar la memoria, y concretamente lo que sería una perspectiva latinoamericana, para lo cual tomaré a Julio Cortázar como referente en un acercamiento estético-político al sandinismo. Un segundo asunto que abordaré será ya propiamente la cuestión de la memoria -la memoria campesina en particular-y su incierta

Mi traducción.

$6 \quad$ A partir de 1982, el gobierno estadounidense financia la guerra de baja intensidad contra los sandinistas. Comienza con remanentes de la Guardia Nacional de Somoza, pero progresivamente va incorporando a campesinos minifundistas y trabajadores temporarios que resienten las políticas de reforma agraria del sandinismo. $\mathrm{Al}$ respecto, ver: Saldaña-Portillo, 109-147.

Belli, El país bajo mi piel; Cardenal, La revolución perdida.

8 Se recordarán las observaciones de Rama sobre las ciudades americanas como "focos de civilizadores" en el espacio de la "barbarie" (La ciudad letrada 16) y la existencia de anillos subalternos que rodean a esa "ciudad escrituraria", uno urbano y mestizo (45), y otro más marginal que "se extendía por la inmensidad de los campos" (46) en donde se hablaban "las lenguas indígenas o africanas que establecían el territorio enemigo" (46). El alzamiento campesino nicaragüense tuvo también un componente étnico en grupos indígenas de la costa caribeña que activaron uno de los escenarios contrarrevolucionarios más complicados. 
inscripción como memoria social. Intentaré conectar estas dos líneas como pertenecientes a una posible crítica de la cuestión de la memoria sandinista en el momento de la transición.

\section{UNA INSCRIPCIÓN APOCALÍPTICA}

Quizá haya cierto automatismo al referirse a la revolución sandinista y al gobierno revolucionario de Nicaragua de los años ochenta invocando como vocabulario la esperanza, la promesa y el sueño (en el sentido de ilusión y porvenir). Este tipo de catálogo finaliza por lo general en el margen opuesto, el del lamento y el duelo, la desesperanza y la distopía?. Este despliegue se asocia también a lo que John Beverley ha llamado el "paradigma de la desilusión" ("Repensando la lucha armada"). Me gustaría contradecir esa conciencia letrada gubernamental a partir de una invocación de Julio Cortázar. La contradicción lleva como horizonte una probable perspectiva (sub)alterna en donde el evento revolucionario podría recobrar algo de su sentido ${ }^{10}$.

Julio Cortázar fue el autor latinoamericano que de manera más sistemática estableció lazos, hizo propaganda por el gobierno revolucionario y trató en sus textos a la revolución sandinista. De este compromiso quedan varias huellas textuales, especialmente su volumen póstumo, Nicaragua tan violentamente dulce $(1984)^{11}$. Se podría decir que Cortázar le dio una inscripción latinoamericana al sandinismo, si es que tomamos por latinoamericano en ese caso específico la ubicación trasnacional de uno de los autores célebres del llamado "boom" latinoamericano, y paradigma de las vicisitudes del autor que trata de ligar una literatura vanguardista con las experiencias

9 Cumple este esquema Sergio Ramírez en sus memorias, ver: Adiós, muchachos...

10 Tomo aquí la definición de evento que ofrece Badiou. Evento sería una irrupción histórica no prevista que enuncia una verdad y produce sujetos, y que, además, requiere fidelidad. Considero, pues, que la revolución sandinista es un evento histórico que compromete política y subjetivamente aun ahora. Para Badiou y el evento, ver: Keucheyan (178-179).Ver también: Badiou, Infinite Thought (43-51).

11 Cortázar participa de las discusiones revolucionarias sobre el evangelio recogidas en el volumen El evangelio de Solentiname de Ernesto Cardenal. Para la recepción de Cortázar por los intelectuales de izquierda en Nicaragua, ver: Ramírez, Estás en Nicaragua. 
revolucionarias de los años sesenta y ochenta, en especial la Revolución cubana y luego la nicaragüense. Se puede discutir si esta sintonía buscada fue meramente voluntarista o utópica, o si estaba sobredeterminada por la historia cultural latinoamericana (el vanguardismo como deseo de salir del naturalismo dominante en el realismo latinoamericano según la tesis de Tulio Halperin Donghi) ${ }^{12}$. De lo que no debe caber duda es que esta búsqueda fue agónica.

Y esa es quizá una de las cosas notables en la inscripción sandinista de Cortázar, precisamente: que podría tipificarse como apocalíptica. Es decir, que en cambio de iniciarse en el borde lexicográfico de la esperanza con su amplio y hasta cierto punto cómodo compás de respiración, comienza en el peligro, el horizonte opaco y la sofocación. El relato "Apocalipsis de Solentiname" funciona como primera incursión literaria y política de Cortázar en Nicaragua, en la que el Paraíso primitivista de la comunidad campesina fundada por Ernesto Cardenal, y representada por la pintura naif, es desplazado por el apocalipsis visual, herencia perversa de las dictaduras: las torturas, asesinatos y desapariciones típicas de los años setenta en toda América Latina.

Se podría esperar en los textos sobre Nicaragua, que Cortázar sigue escribiendo hasta su muerte (entre 1977 y 1984), un cambio hacia un acorde más optimista, y de hecho lo hay. En los textos más informativos de Nicaragua tan violentamente dulce, pensando sin duda en un público internacional de clase media, Cortázar pregona las bondades, buenos proyectos y esperanzas del gobierno sandinista. Sin embargo, en otros textos (quizá también en el tránsito de su propia muerte) no abandona el énfasis apocalíptico y agónico, hecho que parece notable y que refiere a una localización comprometida que trasciende la de las meras relaciones públicas. No parece casual en ese sentido que, para hablar de la Nicaragua de 1984, Cortázar piense en el 1984 de Orwell: una distopía de la modernidad como modelo de los peligros de la soberanía revolucionaria. Por cierta percepción proveniente de las redes comunicacionales, me atrevo a conjeturar que está muy difundida ahora una idea de Cortázar como autor de frases optimistas, dado al ensueño y rozando, cronopios y magas de por medio, ciertas tendencias literarias new age. Quizá el autor

12 Sobre el compromiso de Cortázar, ver también el texto de Ricardo Pigila, "Sobre Cortázar" (Crítica y ficción 83-87). 
de los "ríos metafísicos" vaya siendo apartado por el de cierta estética sesentera y hippie que resulta más cómoda para la dominante cultural del internet. El Cortázar politizado es frecuentemente el otro, es decir, el que descubre de forma evidente la interrelación vital entre modernidad y horror $^{13}$. Quiero proponer que es ese el marco de inscripción sandinista de Cortázar.

En la edición española de Nicaragua tan violentamente dulce, su colección de textos sobre Nicaragua, Cortázar agrega un prólogo en que, probablemente motivado por su cercana muerte, medita de forma crítica sobre el sentido político de la literatura en el contexto del año 1984, que tantas resonancias simbólicas posee. La disonancia entre lo dicho y lo comunicado, o lo interpretable, forma parte de la propuesta discursiva de Cortázar en ese texto. El Idiota, inspirado en Dostoievski, e inesperada forma de saludo con que interpela a Cortázar el artista Roberto Matta, causa alarma porque dice "las cosas más inapropiadas en cualquier circunstancia, y sólo algunos se dan cuenta de que no eran de ninguna manera inapropiadas" (8). El Cortázar que vocaliza lo político incurre en una impertinencia (el lenguaje político que no pertenece al estético). En ese sentido, Cortázar parece intervenir con la creencia de que no hay tal transparencia verbal ofrecida por la ideología (es decir, que el lenguaje político no se basta a sí mismo) sino, más bien, integra un esquema de pulsiones y áreas ocultas y sumergidas cuya revelación debe transponerse y pensarse, en este caso específico, cree Cortázar, con relación a la producción del hombre nuevo (15). ¿Cómo leer la novela de Orwell 1984 desde el 1984 histórico? Estratégicamente, Cortázar identifica la distopía orwelliana en la actitud y la acción imperial de Estados Unidos en la Centroamérica de los años ochenta, y así plantea:

Termino estos apuntes en momentos en que Arimán Reagan empuja imperiosamente sus títeres externos e internos para que destruyan la revolución sandinista en Nicaragua y continúen combatiendo a las fuerzas populares en El Salvador. 1984 [la novela de Orwell] acaba de entrar en su simultaneidad literaria y temporal; las cosas no serán así en el mundo este año, pero sólo lo que está ocurriendo en América Central basta para mostrar

$13 \mathrm{Al}$ respecto, ver las lecturas de Alazraki sobre el desarrollo de la obra narrativa de Cortázar "Imaginación e historia"; y de Moreiras sobre la narración "Apocalipsis de Solentiname". 
uno de los peldaños por los cuales el horror orwelliano sigue descendiendo en su monstruosa voluntad de entropía. Polonia, Guatemala, Afghanistán [sic] son otros peldaños; el lector conoce muchos más en África y en Asia... (17).

Al fondo de la escalera puede esperar la guerra atómica y el final. Cortázar pone sus esperanzas, sin embargo, en el socialismo como "fénix permanente", con capacidad de renovación e invención (17). Uno de los escenarios fundamentales de este proceso inventivo es la producción del hombre nuevo que no debe ser concebido unilateralmente como "revolucionario permanente" lleno de una bondad esencial. En ese sujeto ideológico no se han reconocido, y es la experiencia cubana, las "pulsiones irracionales", lo cual ha conducido al sectarismo ideológico. Tomando como experiencia fundamental el caso de Cuba, Cortázar critica la persecución de homosexuales y de intelectuales en la isla, pensando, además, los horizontes antropológicos más lejanos del ser humano en que las pulsiones y deseos son reconducidos dentro de la nueva sociedad (combatir el machismo es uno de los ejes de tal lucha). El tono de Cortázar aquí suena bastante datado por los debates de la época, y la supuesta proximidad de una libertad erótica y sexual ajena a la ley del valor. La interrelación inevitable entre el entorno apocalíptico y la dificultad casi naturalista de producción subjetiva que Cortázar propone (tan fundamental para producir un socialismo renovado), acentúa la intención agónica. Es decir, cómo producir un sujeto en el que lo hedónico se equilibre con lo social, dando por hecho una índole natural (o inconsciente) cuya presencia no se exorciza con ideología. Desde ese ángulo, no son un entusiasmo fácil ni una esperanza sin fisuras los que vinculan a Cortázar con Nicaragua. El escenario doble de amenaza de destrucción y de dificultad de producción subjetiva, unido a la complicada estabilización de una autonomía nacional, constituyen la difícil apuesta histórica que afrontaba, desde la mirada de Cortázar, la revolución sandinista.

Por supuesto que, históricamente, fue otra la inscripción de estos elementos que se impuso en la llamada opinión pública u opinión dominante. La agonía apocalíptica que Cortázar vislumbrara devino una transición, un término comodín que designa diversos procesos desarrollados a partir de los años ochenta en toda América Latina. Se nombra por lo general con relación a una transición a la democracia política, aunque de manera quizá más decisiva se trata de una transición hacia el neoliberalismo 
global como sistema. Ha sido, por lo general, un discurso optimista muy distanciado de la agonía de los años ochenta. En aquel entonces, Cortázar escribía pensando en bordes nacionales de defensa y de creación de soberanía que conducían a su vez, y paradójicamente, al control (que hoy llamaríamos biopolítico) de los impulsos de la "barbarie" en los sujetos (machismo como pulsión a ser sometida por medio de la educación). El discurso neoliberal ha prodigado en cambio la riqueza de los escenarios de fronteras (más culturales que económicas) que hablan metafóricamente de la nueva circulación global, y ha reconducido la producción subjetiva a la creatividad de los mercados: si hay algo que "controla" lo natural, es el consumo. Aunque la amenaza apocalíptica no ha desaparecido necesariamente, parece tener un papel menos relevante y un perfil mucho más bajo en la recomposición del mundo.

\section{LA RECONVERSIÓN GLOBAL}

En contraste, pues, con la elaboración proyectiva de Cortázar, cuyo marco fue la Guerra Fría, el escenario de memorización del proceso revolucionario sandinista es la reconversión global. Me gustaría detenerme en algunos aspectos de tal escenario, en relación precisamente con cómo condiciona la memoria. La idea principal es que, no obstante las apariencias, el escenario sigue siendo apocalíptico si se considera el proceso posrevolucionario nicaragüense, que desembocó en una guerra civil, como una hecatombe hecha en nombre del liberalismo. Este proceso violento abarca también a las fuerzas revolucionarias que progresivamente, unas de forma más radical que otras, asumen el horizonte liberal como perspectiva pragmática o deseable ${ }^{14}$. En ese contexto, la revolución sandinista cae en la indiferencia, en el sentido de que no se distingue más en su contexto, sobre todo con relación al resto de América Latina o, por lo menos, de Centroamérica, pues se trata y es visto como un solo proceso de transformación. De hecho, la operación de reconversión global de

14 Si bien este proceso es predominante, hay, por supuesto, escenarios y estrategias que resisten una reconversión sin más al liberalismo. Se verá más adelante, en el caso de los hermanos Ernesto y Fernando Cardenal y sus libros de memorias, algunas de estas atenuantes. 
alguna manera unifica a Centroamérica, y se verbaliza en los términos de la transición (que se sobreentiende es hacia el libre mercado) y la democracia, términos contrapuestos al de la guerra civil, que sería el término definitorio de la época revolucionaria. Una racionalidad esperanzadora, ofrecida por la transición, se coloca de manera correctiva frente a una recurrencia secular e irracional encarnada en las revoluciones. La operación de rearme de lo latinoamericano mira al subcontinente como el espacio del duelo por los muertos: un mundo postapocalíptico del que la literatura de Roberto Bolaño sirve como enunciación ya canonizada ( $\mathrm{y}$ en cierto sentido dogmatizada $)^{15}$. En resumen: si Cortázar preveía una transición hacia el socialismo en que el desafío de lo administrativo, soberano y biopolítico confluía en el diseño del (así llamado) "hombre nuevo", el escenario de producción de la memoria del sandinismo está cruzado por aquel antiguo deseo, pero ubicado en el contexto subjetivo en el que la supervivencia y la inserción social implica "tecnologías del yo" específicas y motivadas en gran parte por el neoliberalismo. Esta ubicación doble condiciona, pues, la articulación memorística.

\section{LA CUESTIÓN DE LA MEMORIA SANDINISTA: DISONANCIAS}

En este punto es importante postular que la memoria del sandinismo es una memoria en cierto sentido institucional o gubernamental: la de uno de los pocos movimientos guerrilleros latinoamericanos que logran desmantelar un antiguo régimen y fundar un Estado. El sandinismo, desde la oposición o en el gobierno, sigue siendo, durante el ya largo proceso de transición, un actor político decisivo y fundacional. Existe, en efecto, una memoria del individuo institucional que describe, precisamente, la racionalidad del poder, el pragmatismo que fue necesario para mantenerlo, algunos toques de desencanto por los sueños no cumplidos y la proclamación de los

15 Sintomático del discurso fúnebre por los jóvenes muertos en las lides revolucionarias, aparece en el conocido "Discurso de Caracas", al recibir Bolaño el premio Rómulo Gallegos, y en el que es notoria la trasposición alegórica de la militancia política en el afán literario (Paz Soldán y Faverón, eds. Bolaño salvaje 33-42). Sobre la asociación de la revolución y la lucha armada con la locura, el despropósito y la inmadurez, ver Beverley, "Repensando la lucha armada". 
beneficios de la transición hacia el liberalismo. Estos elementos pueden percibirse en las memorias de Sergio Ramírez, escritor y vicepresidente del gobierno revolucionario: Adiós, muchachos: una memoria de la revolución sandinista (1999). Su planteamiento justificativo característico es algo así como fuimos tras el socialismo pero, casi sin quererlo, logramos la democracia política $^{16}$. O desde mi punto de vista: fuimos tras el plan de soberanía y nos arrastraron las turbulencias de la hecatombe neoliberal. En el texto de Ramírez se traslada potencialmente el momento fundacional del Estado no a la ruptura revolucionaria de 1979, sino al momento de la transición que ocurre a partir de 1990, con el gobierno de Violeta Chamorro. Creo que parte importante de la batalla de la memoria y de la escritura de la historia pasa por definir ese punto fundamental. Recientemente, la poeta Gioconda Belli, rememorando aquella transición, declaró que Chamorro "maternizó a Nicaragua"17, implicando que la expresidenta se convirtió en madre de unas masas divididas por la guerra civil. Nada menos cierto. Con Chamorro se radicalizó el desmantelamiento del Estado y sus responsabilidades sociales, se impuso la ideología de la privatización ideológica de la educación y se retomó la afiliación acrítica con los proyectos de libre mercado y la hegemonía de los Estados Unidos. En otras palabras, parafraseando un cuento clásico de Juan Rulfo se podría decir que ese gobierno "no tuvo madre". Sin embargo, dentro de un modelo memorístico de desilusión posrevolucionaria, se tiende a idealizar de manera menos problemática la transición. La revolución, en cuanto evento, requiere en cambio inscripciones mucho más contradictorias.

En este sentido, hay que recordar que la revolución sandinista fue protagonizada principalmente por sectores populares urbanos y de la clase media y alta, y que el alzamiento campesino y étnico (campesinos del norte de Nicaragua y pueblos indígenas del Caribe nicaragüense) en contra del sandinismo fue quizá el dilema fundamental ético y político del proceso revolucionario. Como se sabe, la lucha del Frente Sandinista se inició en los años sesenta bajo un modelo guevarista del foco guerrillero. Esta estrategia llevó a una serie de derrotas militares y a un aprendizaje político muy importante y plural. Luego de poco más de una década

16 Cf. Adiós muchachos 17.

17 Entrevista en La Prensa, 22 de septiembre de 2013. On line: http:/ /www. laprensa.com.ni/2013/09/22/seccion-domingo/163335-nunca-me-cayo-daniel 
de lucha guerrillera la estrategia del foco guerrillero cambió por una de insurrección en las ciudades y pueblos. Como es usual en Centroamérica, la localización guerrillera en el campo y la montaña conllevó terribles actos de represión estatal sobre los campesinos. La denuncia de tales actos en contra de los derechos humanos se convirtió en un elemento importante en la lucha anti-dictatorial y en el giro político revolucionario de las clases medias y altas $^{18}$. Estas estuvieron motivadas, además, por la prédica de la teología de la liberación que identificó al pobre con la presencia de Cristo en la historia. En este sentido podría hablarse de un populismo de doble vía que confluye en la lucha contra la dictadura: el que desde la doctrina radical de la guerrilla habla del pueblo y el que desde la teología se refiere al pobre. La confusión de ambas figuraciones será un poderoso factor para la movilización revolucionaria.

Esta subjetividad motivadora (el pobre, el pueblo) constituye también una decisiva interpelación de integración nacional bajo un modelo desarrollista. Como ha mostrado Josefina Saldaña, la reforma agraria sandinista buscó no solamente un cambio radical en la estructura de la propiedad de la tierra, sino también producir un nuevo sujeto campesino integrado a la producción agrícola estatal y de cooperativas; la "política agrícola [del sandinismo] fue en sí misma un régimen de sujeción" (111). En otras palabras, el proyecto revolucionario, que intentó de manera precaria un proceso de industrialización agrícola, se propuso procesos de subjetivación en los que resultaba evidente la búsqueda del enlace entre Estado, nación y subalterno. En torno a este fallido programa de subjetivación se entreteje toda una red de la memoria, generalmente por vías etnográficas, con una concepción de sujeto coral que cuenta experiencias, e intenta dar razones de la separación entre razón revolucionaria y acción subalterna ${ }^{19}$. Me voy a detener en una cronología teórica e histórica relacionada con esta red, incluyendo elementos que en apariencia quedan fuera de ella. Así, tendríamos: en primer lugar, el momento del triunfo revolucionario como

18 Ver, por ejemplo, la decisiva participación de Fernando Cardenal al denunciar estos atropellos a los derechos humanos de los campesinos: Sacerdote en la revolución, tomo I (106-125). Ver, asimismo, el testimonio de la campesina Amada Pineda sobre la brutal represión sobre los campesinos, y las múltiples violaciones a que es sometida ella como "castigo", en Randall, Todas estamos despiertas (120-137).

19 Ver, por ejemplo, los libros publicados en 2011 de Soto Joya y López Salinas. 
inscripción administrativa de lo nuevo; en segundo lugar, el momento de transición de la razón revolucionaria socialista a la razón neoliberal, en el que se ve a las élites políticas e intelectuales auto-educándose en medio de la ansiedad sobre la nueva situación. En este mismo momento son importantes los excesos globales en donde se reinscriben tanto el sujeto liberal emancipado como el subalterno desterritorializado.

El término que define la situación de triunfo de la revolución sandinista es el de hegemonía ${ }^{20}$. Al desmantelarse el estado somocista, el sandinismo adquiere una tarea fundacional en que los actores revolucionarios se redefinen a través de la administración del poder y la conducción de la sociedad. Las revoluciones centroamericanas son, como las revoluciones modernas, estratégicamente estatistas, y el sandinismo es también una ideología estatal o una gubernamentalidad ${ }^{21}$. Los cantos del triunfo revolucionario se confunden con los de la instalación del nuevo poder, y en su instalación vibra la cuestión de la producción subjetiva: el concepto de hombre nuevo es el del nuevo administrador de la nacionalidad. Una vez más, hay que considerar que la misma estructura fundacional del Estado está marcada en este caso por lo que he llamado hecatombe liberal: no hay mantenimiento del poder político del sandinismo sin una negociación con el liberalismo económico o una integración a él, asunto que se define a partir de los acuerdos de paz de Esquipulas de 1987. O, en otro sentido, que los planteamientos apocalípticos de Cortázar en cierto sentido "vigilan" el ulterior avatar de la soberanía y el poder constituido. En una metáfora bastante sugerente, Cortázar había visto la consolidación del Estado revolucionario bajo la metáfora de un tigre sostenido por "una irrisoria cadena", en un país en donde "de alguna manera cada uno está jugando con un tigre" (Nicaragua tan violentamente dulce 74). La posibilidad de soberanía revolucionaria era la de la cadena tan frágil que evitaba una especie de retorno a la naturaleza del tigre domesticado. (En todo el modelo cortazariano, no obstante la sofisticación parisina, late la alternativa civilización-barbarie o, para ponerlo en términos más

20 La obvia referencia conceptual remite a Gramsci, pero contemporáneamente aparece bastante mediada por la teorización de Laclau, particularmente, Laclau y Mouffe, Hegemonía y estrategia socialista. Para una crítica del concepto de hegemonía desde términos cercanos a Toni Negri, ver: Beasley-Murray, Posthegemony.

21 Foucault, "Governamentality". 
cercanos a su proyecto, la de civilización-apocalipsis). Esto lleva a una conclusión un poco paradójica (sobre todo si se piensa en contraste con otras experiencias memorísticas): la memoria posrevolucionaria sandinista es una memoria desde la hegemonía y su duelo es también el duelo por lo administrativo, bajo el supuesto de que lo administrativo comprende también los procesos de subjetivación del actor revolucionario. El entrecruce de la hegemonía y el subalterno está cargado de intenciones biopolíticas. Es lo que se podría llamar, según veremos a continuación, la tensión entre el paraíso y la administración.

\section{PARAÍSO Y ADMINISTRACIÓN}

Fernando Cardenal, sacerdote jesuita con una larga militancia revolucionaria, exministro de educación del gobierno sandinista y hermano del poeta Ernesto Cardenal, publicó un artículo titulado "¿Por qué espero ir al Paraíso después de mi muerte?” (El Nuevo Diario, 3 de octubre de 2010). En el artículo explica que cree haber sido fiel a su voto de dedicar su vida a la defensa de los pobres, un juramento hecho a una comunidad marginal urbana de Medellín, cuarenta años atrás. Las memorias en dos tomos de Cardenal, Sacerdote de la Revolución (2008), inician, en efecto, relatando cómo al decidir hacer su Tercera Probación, o noviciado final, en aquel barrio de Medellín, su vida sufrió un vuelco al conocer de cerca la pobreza, lo cual conduce al juramento fundamental de su vida. Las memorias de Cardenal cuentan su progresiva radicalización política, que opera en especial a través del trabajo con jóvenes sandinistas de la clase media y alta que ingresan a la guerrilla durante los años setenta tras un proceso de concientización (el término que indica el proceso de subjetivación del hombre nuevo), de lectura del Evangelio en clave revolucionaria y de radicalización política. Los planos de la memoria son también los de la administración de una micropolítica: cómo despertar conciencia social entre los jóvenes de las clases altas. Esta administración luego adquiere una amplitud estatal: Cardenal dirige la "Cruzada de Alfabetización" de 1980, trabaja con la organización juvenil del sandinismo, la Juventud Sandinista, como una especie de consejero, y luego se ve convertido en ministro de Educación. La lógica administrativa es la lógica del Paraíso, en el sentido que es entendida como un compromiso con la subjetividad nueva, la del 
hombre nuevo, y la del compromiso con los pobres. El hombre nuevo es una especie de semilla de mostaza de la subjetivación (Mateo 13: 31-32). Habría que hacer notar cómo la lógica teológico-política del jesuitismo se articula en este caso con el deseo de producción subjetiva del marxismo. Además, con relación a la constitución más o menos sólida o porosa de esta nueva subjetividad, se puede decir que hay un exceso no controlado por ella: el subalterno, y en el caso concreto de la historia sandinista de una forma fundamental el sujeto campesino y en especial el alzado en armas, el "contra". En su larga lista de errores administrativos y políticos, incluyendo los procesos de corrupción y abusos de poder del sandinismo, Cardenal incluye la cuestión campesina: "Un error muy importante -tal vez el crucial- fue descuidar al campesinado y poner la esperanza en los obreros (y en las élites intelectuales urbanas)" (t. II, 248). Los procesos administrativos estatales y de producción subjetiva colapsan así frente al subalterno.

En términos narrativos y literarios (creo que acá hay que darle oportunidad al saber antiguo de la literatura), Ernesto Cardenal se ha planteado el mismo problema memorístico de cómo armonizar la narración y la visión personal, parcial o "pequeña", con el evento que por su naturaleza pertenece a la multitud. Al contrario de la salida meramente "administrativa" y que adhiere a la ideología de la transición (como ocurre en Sergio Ramírez), Cardenal trata de armar una narrativa que por momentos deviene coral, enfatizando, por ejemplo, el momento políticamente productivo de la insurrección. Para eso recurre a un archivo comunal y personal (cartas, manifiestos, noticias, testimonios) que alegoriza el ingreso democrático de lo múltiple al escenario político. Esta apertura tiene como base una posición teológica combinada con una actitud literaria: el decir la verdad ${ }^{22}$ está atravesado tanto por la herencia jesuítica del ejercicio espiritual (que opera micropolíticamente sobre el sujeto) como el énfasis en lo referencial de la poética poundiana (o exteriorista, en el vocabulario de Cardenal $^{23}$. La articulación teológico-literaria desliga precisamente a

22 Sobre el "decir la verdad" como propuesta de constitución subjetiva motivada por el entrenamiento educativo-religioso, ver: Ernesto Cardenal, Los años de Granada (9-10).

23 Para la interrelación de jesuitismo y poética realista, ver: Leonel Delgado Aburto, "La impureza". 
los sujetos de una esencialidad conceptual (el dogma del hombre nuevo que preocupaba a Cortázar) por una contextualidad figurativa: los sujetos son según sus microhistorias, abiertos a una identidad narrativa (Ricœur 110-114), y sin que pierdan encadenamiento con el marco general (o historia revolucionaria). Esto produce una relación irónica en el enredo de subjetividad e historia. Por supuesto, al leer las memorias de Cardenal considero que el referente histórico y testimonial está también mediado por una trama en cuyo origen confluye "el desarrollo de un carácter y el de una historia narrada" (Ricœur 111). En Cardenal, el designio divino que confluye en la teleología política ordena mucho de la eventualidad de los sujetos, pero estos aparecen también sometidos a un devenir parecido a lo que Ricœur llama identidad ipse. Esta se asocia con una identidad ética a través de la "capacidad de prometer" (113). En el texto memorístico se pone a prueba esa capacidad según las eventualidades de la trama, incluida la del sacrificio y muerte. Hay, pues, algo en la subjetividad (algo narrativo) que sobrepasa el marco de las identidades, las afiliaciones de clase y los caracteres: lo esperable del sujeto es sobrepasado por la identidad ética. Se puede proponer que la instancia que ayuda a mostrar este exceso es la escritura literaria y, en este caso concreto, la articulación narrativa. Un ejemplo ilustrativo es la captura por parte del dictador Somoza de Jorge Ribas Montes, conspirador antidictatorial en la rebelión de abril de 1954. Miremos la escena de escritura que Cardenal propone:

Lo llevaron a La Loma [la Casa Presidencial y cárcel de los opositores políticos], y dijo que contaría todo, a condición de que fuera una declaración formal; pidió papel y lápiz, y comenzó una larga declaración, contando muchas aventuras de su vida (como el intento de matar a Carías, su participación en la revolución de Figueres, su lucha contra Trujillo, la organización de la invasión de abril), y su relato se alargó tanto que cuando lo terminó ya había pasado el furor de Somoza, su sed de venganza se había saciado con todos los asesinatos, y así es que quedó vivo. Pero dos años después, cuando el ajusticiamiento de Somoza, lo mataron en la cárcel. Cuentan que llevaba siempre un rosario al cuello ( $L a$ revolución perdida 22).

Con base en una escena de escritura, Cardenal logra insuflar épica a la historia fragmentada que podría, por otra parte, apuntar a una santidad figurativa (el rosario al cuello). La escena es, además, alegórica porque proyecta una sombra larga sobre el relato o se refleja de vuelta en el 
texto que leemos: es decir que organiza el encadenamiento de historias con la historia revolucionaria. Al verse en el espejo de quien escribe en condiciones de prisión y condena, la memoria dice algo de su condición histórica y de verdad. En resumen: la opción por la verdad parte de una ética de trabajo sobre sí (esta vez referida a una práctica teológica) ${ }^{24}$ que confluye en una estética literaria, en la que subraya el valor realista de la pequeña historia ${ }^{25}$.

\section{EXCESOS GLOBALES: LA MEMORIA REVUELTA}

Si los años ochenta fueron los años del concepto de hegemonía, los noventa van a ser los del subalterno. La teorización proviene del fracaso postcolonial de la India y de la localización de un (nuevo) sujeto histórico en un accionar político no reconocido como tal: la rebelión campesina ${ }^{26}$. En los estudios latinoamericanos se investigaron los intersticios entre Estado y nación, así como el agotamiento de los paradigmas que dieron sentido a ese vínculo: la transculturación, por ejemplo ${ }^{27}$. Asimismo, se ha investigado el lugar postnacional de ese subalterno ahora migrante y disciplinado por la economía global ${ }^{28}$. Algunos hablan incluso más recientemente de un paradigma posthegemónico (Beasley-Murray). ¿Cómo se vincula todo

24 El decir la verdad, como se recordará, es una de las preocupaciones fundamentales del último Foucault, ver: La bermenéutica del sujeto. En Foucault la verdad de sí y la práctica de escritura confluyen con las tecnologías del yo.

25 Aunque no es el espacio para desarrollar el asunto de la relación entre la estética literaria realista del "exteriorismo" de Cardenal y su escritura memorística, se puede argumentar una crisis histórica y personal (fin de la revolución, vejez, etc.) que lo lleva a revisar y repensar, por medio de la autobiografía, los principios ordenadores de su estética. Esta revisión llega a formar parte, a su vez, de su estética literaria, si bien sus principios de interpretación son diferentes a los que orientarían una lectura exclusiva de la poesía.

26 El texto paradigmático es el de Guha (Elementary). Ver, asimismo, las importantes colecciones de Guha y Spivak, en Guha, A Subaltern Studies Reader.

27 Véase: Beverley, Subalternidad y representación. Particularmente interesante para el caso de las narrativas revolucionarias en Centroamérica resulta el libro de Ileana Rodríguez, Women, Guerrillas and Love.

28 Un acercamiento fundamental es el de Gareth Williams. 
esto con el estado de la memoria del proceso sandinista, en especial la memoria campesina?

La transición del sandinismo de los ochenta a los gobiernos conservadores de los noventa implicó un pacto superestructural en que resultaron fundamentales los vínculos familiares de las cúpulas políticas ${ }^{29}$. La memoria, además de administrativa o nostálgica de la administración (por ejemplo, las ya mencionadas memorias políticas de Sergio Ramírez), también incluye muchos rasgos de auto-educación. Se resguarda a los pobres como sentimiento o sentimentalidad. La noche de la derrota electoral del sandinismo en 1990, el padre Fernando Cardenal visita a una niña de la clase media, de 11 años de edad, de la que se sentía responsable por su formación subjetiva y política:

Yo había tenido en ella algo de influjo en la formación de sus valores, así que llegué después de la media noche, estaban esperando los resultados por los medios de comunicación. Y comencé preguntándole a Ana Margarita: "¿Por quién estamos trabajando en esta revolución?". "Por los pobres", me contestó. Le volví a preguntar: “¿Podríamos seguir trabajando por los pobres si perdemos las elecciones?". "Sî" me contestó. Entonces le dije que habíamos perdido las elecciones pero que podríamos seguir trabajando siempre por los pobres. Conversamos un rato y se quedó con una gran tristeza pero en paz, no se rompió (t. II 232).

Aquí se puede ver que la pérdida del poder político implica un reacomodamiento de la producción subjetiva. Los pobres pasan a constituirse como mero afecto de las clases medias y altas, desplazadas de sus labores de administración dentro de un proyecto nacional. La localización de las clases subalternas como afecto indica una potencialidad (el resguardo de los valores revolucionarios y el compromiso) cuyo devenir, sin embargo, se actualiza dentro de un mundo progresivamente reconfigurado por el liberalismo. Si bien en estas condiciones la teología de la liberación mantiene algo de su radicalidad política (como se percibe sin duda en las memorias de Fernando Cardenal), el marco institucional de la transición posee una marca y orientación indudablemente liberal. 
Se abre, es cierto, un forcejeo entre retóricas tensionadas y revueltas que induce a reagrupamientos y contradicciones dentro del sandinismo.

Entretanto, durante los años noventa y la primera década del siglo, excombatientes de la contra y del ejército sandinista pasaron a protagonizar levantamientos en que se mezclaban reivindicaciones sociales y bandidaje. Son los llamados re-contras y re-compas, que cuando se combinaron, formaron los llamados revueltos ${ }^{30}$. Los revueltos constituyen otra de las versiones de la memoria (en realidad una memoria clausurada) en el momento potencialmente posthegemónico. De hecho, su propia identidad aparece muy cifrada tras de los seudónimos, el enigma de sus luchas, e incluso decapitaciones que terminan por borrar sus rostros ${ }^{31}$. Si la localización no-administrativa y meramente afectiva de "los pobres" constituye un problema de auto-educación de la élite, los revueltos constituyen un enigma inscrito en lo global: la aplicación de programas neoliberales de ajuste como parte del acuerdo de las elites, en un contexto de posguerra produce este tipo de subjetividades y actores "pre-políticos" inesperados ${ }^{32}$.

Además de la subjetividad y memoria afectiva que viene por vía de los restos de la teología de la liberación, el momento global también implica la adscripción a una racionalidad subjetiva liberal en que la emancipación se articula en el terreno personal. Resulta interesante al respecto el libro de entrevistas y testimonios de Margaret Randall, Las hijas de Sandino. Las narrativas de emancipación femenina tienden a estar en este caso centradas en el tránsito desde la experiencia administrativa, cuyo horizonte es el proyecto nacional revolucionario, a una narrativa de la emancipación personal. Casi todas estas mujeres tuvieron puestos de administración gubernamental más o menos destacados. Cuando se desvanece el poder revolucionario se rearticula la memoria pero ya no en torno a "los

30 Para una interpretación de los rearmados y revueltos desde el concepto de Hobsbawm de "bandoleros sociales", ver: Verónica Rueda, "Los rearmados de Nicaragua".

31 El caso probablemente más dramático es el del Frente Unido Andrés Castro (FUAC) compuesto por excombatientes sandinistas y desarticulado por el Ejército nacional. Al respecto, ver: José Luis Rocha, "Breve, necesaria y tormentosa historia del FUAC".

32 Guha elabora una crítica al concepto de las rebeliones campesinas como "prepolíticas", ver: Elementary aspects (5-6). 
pobres" como en el caso de Fernando Cardenal, sino más bien en torno a ideologías focalizadas y fragmentadas. Sugerente es, por ejemplo, la narrativa de Sofía Montenegro (Randall, Las hijas de Sandino 374-403), su tránsito desde el trabajo como comunicadora en el diario oficial del sandinismo a impulsora de un grupo feminista, todo narrado como una experiencia de emancipación personal. La pequeña historia autobiográfica también lleva algo de la fragmentación que trae la globalidad, e implica un olvido fundamental: el del deseo administrativo maximalista que permeó a los intelectuales y que implicó una interpelación (por cierto, equívoca) a las clases bajas, en especial los campesinos. En ese caso es sintomática la novela autobiográfica de Gioconda Belli, El país bajo mi piel, que tiene como motivo la narrativa del triunfo individual de una escritora famosa que pretende que en su solidez subjetiva se vea el país entero, incluyendo la cronología revolucionaria. Este tipo de narrativa señalaría un borde muy importante de la memoria sandinista: aquel que roza el modelo liberal de autobiografía en que un sujeto vive su avatar vital y biográfico como proceso de secularización (Beverley, Una modernidad obsoleta 133), rompiendo así el fundamento heterológico y político instituido por las versiones teológicas (del tipo de los hermanos Cardenal) o del vanguardismo radicalizado (en la estrategia mostrada por Cortázar). Lo evidente es, pues, que la memoria del sandinismo no es una y en singular, sino, al contrario, plural y contradictoria, en un compás que va de la aceptación del liberalismo bajo el oropel de la narrativa revolucionaria privatizada, al mantenimiento problemático de un horizonte revolucionario ${ }^{33}$.

\section{Del SUbALTERNo}

Aquí es importante volver a postular que uno de los ejes problemáticos entre el individualismo liberal y la tensión heterológica es la revuelta campesina. De hecho, podría decirse que en los años ochenta hubo dos guerras campesinas significativas en Centroamérica. Por una parte, la guerrilla

33 Las pugnas y contradicciones dentro del sandinismo fueron frecuentes tanto en el período previo al triunfo revolucionario como durante el gobierno. En este último caso estuvo en debate el tipo de proyecto político y cultural. Al respecto de estos debates, ver: Dawes. 
del FMLN en El Salvador logró movilizar a su favor "extensas masas campesinas" (Torres Rivas 19) vinculadas a un "poderoso movimiento de masas" urbanas y sindicales, logrando conformar "un ejército de 10 mil hombres" (y mujeres, habría que agregar), "hecho sin precedentes en la historia de las revoluciones en el mundo" (Torres Rivas 22). Por otra parte, el ejército campesino alzado en contra del sandinismo fue conocido generalmente como "la contra" y también como "la resistencia". Salvador Martí explica que:

La base social de la "contra" no se diferenciaba mucho de aquellos ejércitos campesinos que protagonizaron rebeliones contra las pretensiones modernizadoras y centralistas emprendidas por los gobiernos modernizantes de finales del siglo XIX e inicios del XX en Europa meridional y América del Sur (102).

Frente a este hiato entre modernización y sujeto social, cabe preguntarse por el alcance de las narrativas concebidas como alegorías de la democratización y la emancipación. $\mathrm{O}$, más concretamente, qué pruebas tenemos de que la ocupación de síasumida en su valor ético y cultural rendirá fruto político con sentido democrático $¿ N o$ hemos corrido el riesgo de pasar del presentimiento de un apocalipsis global en los términos planteados por Cortázar a un "pentecostés privado" 34 e ideológico en que se subsume en la subjetividad lo heterogéneo político? Las formas de responder dependen a veces del vocabulario con que se teoriza la localización de las clases subalternas en los relatos histórico-políticos. En todo caso, la cuestión de la hegemonía estatal-nacional sigue siendo una referencia clave del debate: la falencia en la política de inclusión ha dibujado un panorama melancólico para la memorización fluida de "lo bueno" de la revolución. ¿Los campesinos alzados en armas son "bárbaros", retrasados frente al relato de la modernidad como los miraba el vice-presidente Sergio Ramírez en los años ochenta (Confesión 51), o son especie de "buenos salvajes" que resguardan la identidad, como los vio a su vez otro exvicepresidente de Daniel Ortega (cf. Morales Carazo 14), o son guerreros postmodernos localizados más allá de la hegemonía, como hemos pensado algunos a veces usando las anteojeras postcoloniales (Delgado Aburto, "De la memoria")? Como es evidente en la pregunta, 
las respuestas apuntan a formaciones políticas disímiles: el desarrollismo que Ramírez piensa desde la administración estatal; el patriarcalismo conservador que Morales Carazo retoma de las tradiciones intelectuales nacionales; o una búsqueda más radical constituida como espacio de una batalla por la memoria. En otras palabras: lo que está en discusión como macrohistoria en el respaldo de las memorizaciones del sandinismo es la persistencia de una historia desarrollista en que las subjetividades deberían confluir en una articulación soberana-nacional. Desde la memoria se puede reincidir en ese esquema desde formas autobiográficas, liberales o heterológicas, o desde ámbitos melancólicos, pero incluso en las versiones más democráticas opera una lógica de desplazamiento y metaforización de los sujetos campesinos ${ }^{35}$. Es preciso, pues, marcar un límite gnoseológico a la estrategia victoriosa del tipo mostrado por Ernesto Cardenal en que se equilibran la historia y la microhistoria en la identidad narrativa. Si lo subalterno (en este caso campesino) queda suelto en las narrativas de la memoria, constituiría también una instancia de clausura eventual en una historia no finalizada que sigue esperando por una democratización radical. Cabe preguntarse, por último, si se podrán proyectar en el momento agónico de Cortázar las demandas disonantes de la memoria de la revolución sandinista. Propondría plantear esa proyección en torno a la identidad entre modernidad y horror. Cortázar establece esa identidad y su problemática paralela: la cuestión del "hombre nuevo" (entre la santidad y la eventualidad narrativa), y la cuestión de la soberanía/ hegemonía (incompletas y bordeadas por hecatombes y barbaries).

\section{BIBLIOGRAFÍA}

Alazraki, Jaime. "Imaginación e historia en Julio Cortázar". Hacia Cortázar: aproximaciones a su obra. Jaime Alazraki, ed. Barcelona: Anthropos, 1994. 299-322. Impreso.

35 Sobre la tensión entre tropos y narrativa autobiográfica y testimonial, ver: Doris Sommer, "Sin secretos". 
Badiou, Alain. Infinite Thought: Truth and the Return to Philosophy. Oliver

Feltham y Justin Clemens, eds. y trads. Londres: Continuum, 2007. Impreso.

Beasley-Murray, Jon. Posthegemony: Political Theory and Latin America.

Minneapolis: University of Minnesota Press, 2010. Kindle

Beldi, Gioconda. Elpaís bajo mi piel: memorias de amor y guerra. Madrid: Plaza \& Janés, 2000. Impreso.

"Nunca me cayó bien Daniel Ortega". Entrevista en La Prensa, 22 de septiembre de 2013. Web. http://www.laprensa.com.ni Consultado 28-11-2013.

Bendaña, Alejandro, ed. Una tragedia campesina: testimonios de la Resistencia. Managua: CEI, 1991. Impreso.

Beverley, John y Hugo Achugar, eds. La voz del otro: testimonio, subalternidady verdad narrativa. Guatemala: Universidad Rafael Landívar, 2002. Impreso.

BeVERLey, John. Una modernidad obsoleta: estudios sobre el barroco. Los Teques: Fondo Editorial A.L.E.M., 1997.

Subalternidad y representación: debates en teoría cultural. Madrid: Iberoamericana-Vervuert, 2004. Impreso.

"Repensando la lucha armada en América Latina". Sociohistórica, segundo semestre 2011. 163-177.

Bolaño, Roberto. "Discurso de Caracas". Bolaño salvaje. Edmundo Paz Soldán y Gustavo Faverón, eds. Barcelona: Candaya, 2008. 33-42. Impreso.

Cardenal, Ernesto. Elevangelio de Solentiname. Managua: Nueva Nicaragua, 1983.

Los años de Granada. Managua: anamá, 2004. Impreso.

La revolución perdida. Managua: anamá, 2004. Impreso.

Cardenal, Fernando. Sacerdote en la revolución: memorias. (dos tomos). Managua: anamá, 2008.

Cardenal, Fernando. “¿Por qué espero ir al Paraíso después de mi muerte?”. El Nuevo Diario. 3 de octubre de 2010. Web. http://www. elnuevodiario.com.ni/opinion/84845 Consultado 29-11-2013.

Cortázar, Julio. Nicaragua tan violentamente dulce. Barcelona: Muchnik, 1984. Impreso. 
Cortez, Beatriz. "La construcción local de la memoria: fotografías del Museo Comunitario Kaqjay de Patzicía, Guatemala". Revista Iberoamericana. 242 (2013): 227-242. Impreso.

Dawes, Greg. Aesthetic and Revolution: Nicaraguan Poetry, 1979-1990. University of Minnesota Press, 1993.

Delgado Aburto, Leonel. "De la memoria política, los que se narran y los fragmentos". La prensa. 8 de diciembre de 2002.

"La impureza de lo conversacional: vanguardia, autobiografía e historia en los tránsitos textuales de José Coronel Urtecho". Atenea. 507 (2013): 65-78. Impreso.

Foucault, Michel. "Governamentality". Power: Essential Works of Foucault 1954-1984 (Volume Three). James D. Faubion, ed. New York: The New Press, 1994 (201-222). Impreso.

La hermenéutica del sujeto. México: FCE, 2001.

Guha, Ranajit, y Gayatri Chakravorty Spivak, eds. Selected Subaltern Studies. Nueva York: Oxford University Press, 1988.

Guha, Ranajit, ed. A Subaltern Studies Reader 1986-1995. Minneapolis: Minnesota University Press, 1997.

Guha, Ranajit. Elementary Aspects of Peasant Insurgency in Colonial India. Durham: Duke University Press, 1999. Impreso.

Halperin Donghi, Tulio. "Nueva narrativa y ciencias sociales hispanoamericanas en la década del sesenta". Más allá del boom: literatura y mercado. Ángel Rama, ed. Tucumán: Folios, 1984. 144-165. Impreso.

Keucheyan, Razmig. The Left Hemisphere: Mapping Critical Theory Today. London: Verso, 2013. Impreso.

Laclau, Ernesto y Chantal Mouffe. Hegemonia y estrategia socialista. Madrid: Siglo XXI, 1987. Impreso.

López Salina, G. EnRiQue. La guerra que no existió. Managua: EDITARTE, 2011. Impreso.

Martí I Puig, Salvador. "Algunas reflexiones políticamente incorrectas sobre Nicaragua". Estrategias de poder en América Latina: VII EncuentroDebate América Latina ayer y hoy. García Jordem, Pilar y otros, eds. Barcelona: Universidad de Barcelona, 2000. Impreso.

Martínez Rivas, Carlos. La insurrección solitaria. Madrid: Visor, 2006. 
Morales Carazo, Jaime. La contra: anatomía de una múltiple traición. México, Planeta, 1989. Impreso.

Moreiras, Alberto. "Producción heterológica en Cortázar". Tercer espacio: literatura y duelo en América Latina. Santiago: Universidad Arcis, 1999. 355-385.

Piglia, Ricardo. "Sobre Cortázar". Crítica y ficción. Buenos Aires: Siglo Veinte, 1990. 82-87. Impreso.

Rama, Ángel. La ciudad letrada. Hanover: Ediciones del Norte, 1984. Impreso.

Ramírez, Sergio. Estás en Nicaragua. Managua: Nueva Nicaragua, 1986. Impreso.

Confesión de amor. Managua: Nicarao, 1991.

Adiós muchachos: una memoria de la revolución sandinista. San José: Aguilar, 1999. Impreso.

RANDALl, MARgaret. Todas estamos despiertas: testimonios de la mujer nicaragüense boy. México: Siglo XXI, 1989.

Las hijas de Sandino. Managua: anamá, 1999.

Riceur, Paul. Caminos del reconocimiento. Madrid: Trotta, 2005. Impreso.

RochA, José LuIs. "Breve, necesaria y tormentosa historia del FUAC". Envío 232 (2001). Web: http://www.envio.org.ni/articulo/1089 Consultado 28-11-2013.

Rodríguez, Ileana. Women, Guerrillas \& Love: Understanding War in Central America. Minneapolis: University of Minnesota Press, 1996.

Rueda, Verónica. "Los rearmados de Nicaragua: los últimos bandoleros sociales". Cinteotl 2 (2007): 1-34. Web.

Rulfo, Juan. "Luvina". Pedro Páramo. El llano en llamas. Santiago: Planeta, 2010. 229-239. Impreso.

Saldaña-Portillo, María Josefina. The Revolutionary Imagination in the Americas and the Age of Development. Durham: Duke University Press, 2003. Impreso.

SOMmer, Doris. "Sin secretos". La voz del otro: testimonio, subalternidady verdad narrativa. John Beverley y Hugo Achugar, eds. Guatemala: Universidad Rafael Landívar, 2002. 147-165. Impreso.

Soto Joya, Fernanda. Ventanas en la memoria: recuerdos de la revolución en la frontera agrícola. Managua: UCA Publicaciones, 2011. Impreso. 
TORRES Rivas, EDELBERTO. Revoluciones sin cambios revolucionarios: ensayos sobre la crisis en Centroamérica. Guatemala: F\&G, 2011.

Vilas, Carlos. "Asuntos de familia: Clases, linaje y política en Nicaragua". Polémica 18 (1992): 5-30. Impreso.

Williams, Gareth. The Other Side of the Popular: Neoliberalism and Subalternity in Latin America. Durham: Duke University Press, 2002. Impreso.

Recepción: 29.11.2013

Aceptación: 27.12.2013 